\title{
O papel da enfermagem na assistência a vítima de estupro
}

\author{
The role of nursing in assisting victims of rape \\ El papel de la enfermería en la asistencia a las víctimas de violación
}

Recebido: 14/03/2021 | Revisado: 21/03/2021 | Aceito: 26/03/2021 | Publicado: 04/04/2021

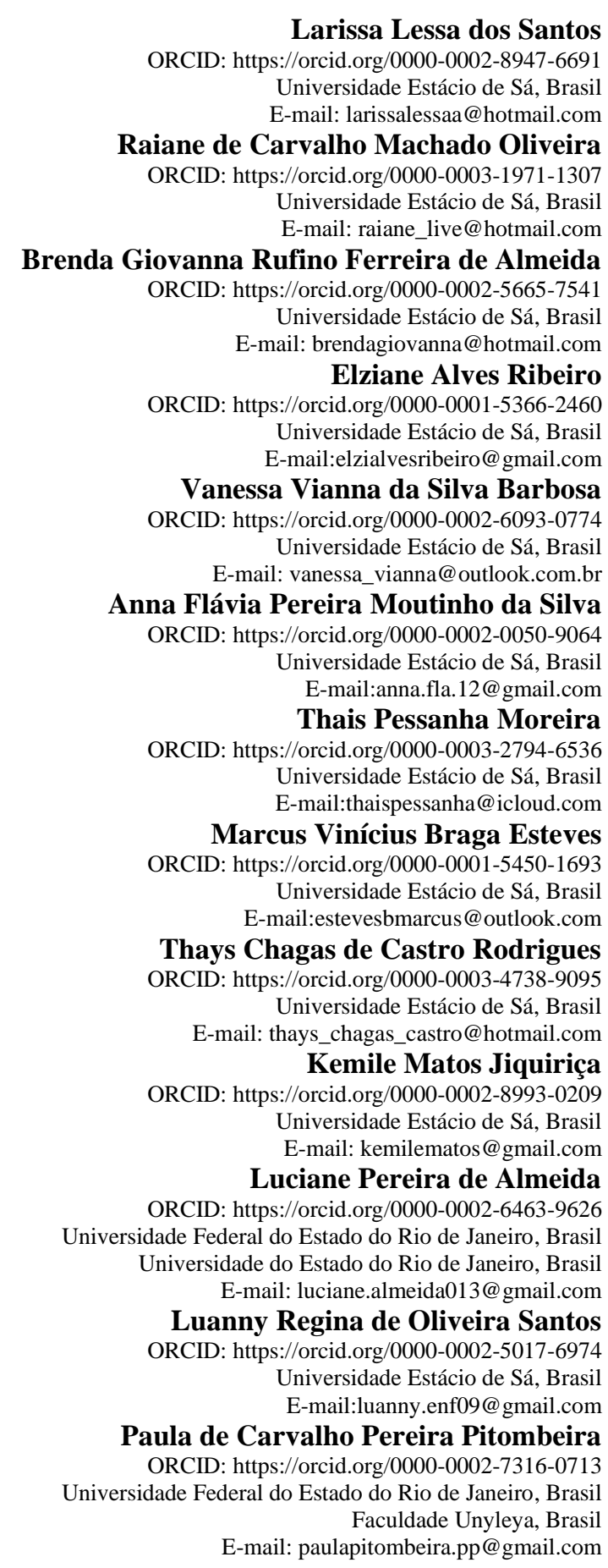

\section{Resumo}

Introdução: A legislação brasileira define estupro como o tipo mais grave de abuso sexual. Estupro consiste em qualquer ato praticado, com finalidade sexual sem o consentimento de uma das partes envolvidas, violando o direito do outro. Objetivos: Identificar o papel do enfermeiro na assistência prestada à vítima de estupro e analisar a 
assistência de enfermagem frente às vítimas de estupro. Metodologia:Trata-se de um estudo com abordagem qualitativa, do tipo revisão integrativa, que teve como base de dados a Biblioteca Virtual de Saúde Enfermagem usando os Descritores em Ciências da Saúde (DeCS Enfermagem; Estupro; Assistência de enfermagem. Foram selecionados artigos completos, em língua portuguesa e inglesa publicados entre 2011 a 2021 . Ao fim da aplicação dos critérios, emergiram 6 artigos para leitura minuciosa e construção do conteúdo. Resultados e discussão:Foram elaboradas duas categorias para análise de dados. Categoria I - Aspectos socioculturais do estupro; Categoria II O profissional de enfermagem frente às vítimas de estupro. Considerações finais: Conclui-se que o enfermeiro é um profissional protagonista na assistência à vítima de estupro e que faz-se necessário a realização constante de capacitações para melhoria do atendimento.

Palavras-chave: Enfermagem; Estupro; Assistência de enfermagem.

\begin{abstract}
Introduction: Brazilian law defines rape as the most serious type of sexual abuse. Rape consists of any act performed, for sexual purposes without the consent of one of the parties involved, violating the right of the other. Objectives: To identify the role of the nurse in the assistance provided to the rape victim and to analyze the nursing assistance in relation to the rape victims. Methodology: This is a study with a qualitative approach, of the integrative review type, which had as a database the Virtual Health Library Nursing using the Health Sciences Descriptors (DeCS Nursing; Rape; Nursing assistance. Articles were selected complete, in Portuguese and English, published between 2011 and 2021. At the end of the application of the criteria, 6 articles emerged for thorough reading and construction of the content. Results and discussion: Two categories were developed for data analysis Category I - Socio-cultural aspects of rape; Category II -The nursing professional facing the victims of rape. Final considerations: It is concluded that the nurse is a leading professional in assisting the rape victim and that it is necessary to constantly carry out training to improve care.
\end{abstract}

Keywords: Nursing; Rape; Nursing care.

\title{
Resumen
}

Introducción: la ley brasileña define la violación como el tipo de abuso sexual más grave. La violación consiste en cualquier acto realizado, con fines sexuales sin el consentimiento de una de las partes involucradas, violando el derecho de la otra. Objetivos: Identificar el rol de la enfermera en la asistencia brindada a la víctima de violación y analizar la asistencia de enfermería en relación a las víctimas de violación. Metodología: Se trata de un estudio con abordaje cualitativo, de tipo revisión integradora, que tuvo como base de datos la Biblioteca Virtual en Salud Enfermería utilizando los Descriptores de Ciencias de la Salud (Enfermería DeCS; Violación; Asistencia de enfermería. Se seleccionaron artículos completos, en portugués e inglés, publicado entre 2011 y 2021 . Al final de la aplicación de los criterios, surgieron 6 artículos para la lectura y construcción profunda del contenido. Resultados y discusión: Se desarrollaron dos categorías para el análisis de datos Categoría I - Aspectos socioculturales de la violación; Categoría II - El profesional de enfermería frente a las víctimas de violación. Consideraciones finales: Se concluye que el enfermero es un profesional líder en la atención a la víctima de violación y que es necesario realizar una formación constante para mejorar la atención.

Palabras clave: Enfermería; Rapé; Cuidado de enfermera.

\section{Introdução}

A legislação brasileira define estupro como o tipo mais grave de abuso sexual. Estupro consiste em qualquer ato praticado, com finalidade sexual sem o consentimento de uma das partes envolvidas, violando o direito do outro. É considerado um crime violento e hediondo, ou seja, de extrema gravidade. O mesmo recebe um tratamento diferenciado e mais rigoroso do que as demais infrações penais para o mesmo tipo de crime, sendo considerado inafiançável (Lei $\mathrm{n}^{\circ} 12.015$, de 2009)

O estupro é caracterizado porser praticado mediante violência real, como uma agressão ou mediante uma violência presumida, quando praticado contra menores de 14 anos, alienados mentais ou contra pessoas que não puderem oferecer resistência.Quando praticados contra menores de 14 anos, é classificado ainda como estupro de vulnerável. (Lei nº 12.015, de 2009)

De acordo com o Código Penal Brasileiro, em seu artigo 213, é considerado estupro constranger alguém, mediante violência ou grave ameaça, a ter conjunção carnal ou a praticar ou permitir que com ele se pratique outro ato libidinoso. Atualmente, a pena no Brasil é de 6 a 10 anos de reclusão para o criminoso, podendo chegar até 8 a 12 anos, em casos em que 
ocorra lesão corporal à vítima. Em situações nas quais a vítima possui entre 14 a 18 anos de idade, a pena é de 12 a 30 anos se da conduta resultar em morte (Lei $\left.\mathrm{n}^{\circ} 12.015,2009\right)$.

Até 2009, a lei definia estupro como "constranger mulher à conjunção carnal, mediante violência ou grave ameaça.Deixava-se implícito que apenas a mulher poderia ser a vítima, e somente o homem poderia ser o agente ativo. Somente com a Lei 12.015/2009, o artigo 213 do Código Penal a expressão "mulher" foi substituída por "alguém". Logo, cabe salientar, que o estupro pode ocorrer entre pessoa do mesmo sexo, ou uma mulher sendo a agressora e o homem a vítima (Lei $\left.\mathrm{n}^{\circ} 12.015,2009\right)$.

Atualmente a jurisprudência brasileira concede à palavra da vítima como de maior valor probatório em crimes sexuais.

A ausência de laudo pericial conclusivo não afasta a caracterização de estupro, porquanto a palavra da vítima tem validade probante, em particular nessa forma clandestina de delito, por meio do qual não se verificam, com facilidade, testemunhas ou vestígios. (STJ, Sexta Turma, AgRg no AREsp 160.961/PI, Rel. Min. Sebastião Reis Júnior, julgado em 26/06/2012)

Como forma de evitar casos de condenações injustas baseadas em mentiras, falsas memórias, falsos reconhecimentos, é recomendado que exista um conjunto probatório harmônico, coerente e capaz de elevar os indícios da autoria do delito. Então a palavra da vítima é devidamente validada (Lopes JR., 2018. p. 457).

A violência acontece com todo o tipo de público, sejam homens, mulheres, crianças, adolescentes, travestis ou transgêneros. Pessoas que sofrem esse tipo de abuso levam marcas psicológicas para o resto de suas vidas, porém, cada indivíduo contextualiza e lida com o fato de forma única. $O$ ato de agressão sexual também pode ser aparente na vítima de forma física, a partir de quadros depressivos, ansiedade e síndromes do pânico, sendo identificado por profissionais de saúde (Dempsey, 2002).

Segundo o Ministério da Saúde, ao dar entrada no serviço de saúde, a pessoa vítima de violência sexual necessita de acolhimento holístico, fator primordial para se implementar a humanização da assistência de enfermagem, e para que se estabeleça vínculo de forma adequada entre profissional e paciente. O manejo com esse cliente e a abordagem especializada devem ser entendidos como fundamental para se realizar esse atendimento (Brasil, 2012).

Diante da problemática exposta, o trabalho em questão apresenta como objeto de estudo a assistência de enfermagem prestada às vítimas de estupro. Os objetivos determinados são identificar o papel do enfermeiro na assistência prestada à vítima de estupro e analisar a assistência de enfermagem frente às vítimas de estupro. O estudo se justifica a partir da dificuldade dos profissionais de saúde, acadêmicos e sociedade em discutir sobre o assunto, principalmente por englobar aspectos políticos e pré-conceitos sociais. Foi observada uma lacuna do conhecimento a respeito da temática, o que torna imprescindível a pesquisa científica nesta área.

A relevância para os acadêmicos de enfermagem se faz com a intenção de informar e buscar uma reflexão sobre a temática, uma vez que será de grande importância para a assistência realizada por eles no futuro; social por levar à sociedade o conhecimento científico ao qual, de costume, ela não teria acesso, e para fins de pesquisa, já que outros poderão então fazer uso dos dados encontrados aqui reunidos e analisados. A temática escolhida vem ganhando grande proporção pela repercussão do caso "estupro culposo" que ocorreu em 2020, sendo assim, o estudo torna-se indispensável para acadêmicos, pesquisadores e sociedade. 


\section{Metodologia}

Trata-se de um estudo de abordagem qualitativa, do tipo revisão integrativa, na qual foi abordada a assistência de enfermagem frente às vítimas de estupro. Segundo Bardin (2016), a pesquisa qualitativa é a que se fundamenta principalmente em análises qualitativas, caracterizando-se, em princípio, pela não utilização de instrumental estatístico na análise dos dados.

Segundo Ganong (1987) a revisão integrativa da literatura propõe o estabelecimento de critérios bem definidos sobre a coleta de dados, análise e apresentação dos resultados, desde o início do estudo, a partir de um protocolo de pesquisa previamente elaborado e validado.

Para a construção do artigo optou-se pela revisão integrativa da literatura, que consiste na elaboração de análise abrangente de artigos, estabelecendo critérios de investigação técnico-científico para coletar dados, analisar e apresentar resultados. As informações obtidas podem sinalizar achados que requerem mais atenção no meio científico, visando melhorias na prática profissional (Ganong, 1987).

A revisão integrativa necessita ser guiada por etapas. De acordo com Mendes, Silveira e Galvão (2008) essa revisão deverá conter seis etapas: 1) Estabelecimento de hipótese ou questão de pesquisa; 2) Amostragem ou busca na literatura; 3) Categorização dos estudos; 4) Avaliação dos estudos incluídos na revisão; 5) Interpretação dos resultados; 6) Síntese do conhecimento ou apresentação da revisão.

A estratégia de identificação e seleção dos artigos originou-se através da busca da Biblioteca Virtual de Saúde (BVS), no mês de fevereiro de 2021. Iniciou-se a busca de materiais que contivessem em seu resumo os descritores em ciências da saúde (DeCS) Enfermagem; Estupro; Assistência de enfermagem. Foram adotados os seguintes critérios para seleção dos artigos: materiais completos, em língua portuguesa e inglesa, no formato de artigo e com recorte temporal de dez anos (20112021) devido a escassez de pesquisas sobre a temática. Os critérios de exclusão foram os estudos duplicados, desatualizados e com irrelevância para o viés pesquisado neste trabalho.

Emergiram 6 artigos com os critérios citados, os quais procederam-se à leitura minuciosa para a construção do conteúdo, destacando aqueles que responderam ao objetivo proposto pelo estudo, com intuito de organizar os dados.

Os artigos foram tabelados por título, autores, ano de publicação, periódico, objetivos, resultados e conclusão. A partir de então iniciou a análise bibliométrica destes que foram agrupados por similaridade sob forma de categorias.

\section{Resultados e Discussão}

Os resultados apresentados no estudo mostram a importância do estudo sobre a temática abordada, sendo descritas no Quadro 1. 
Quadro 1. Artigos selecionados.

\begin{tabular}{|c|c|c|c|c|c|}
\hline Título & Autores & Objetivo & Metodologia & Evidências & Conclusão \\
\hline $\begin{array}{c}\text { Perfil das } \\
\text { ocorrências } \\
\text { policiais de } \\
\text { violência contra a } \\
\text { mulher }\end{array}$ & $\begin{array}{c}\text { Daniele } \\
\text { Ferreira } \\
\text { Acosta; } \\
\text { Vera Lucia de } \\
\text { Oliveira } \\
\text { Gomes; } \\
\text { Edison Luiz } \\
\text { Deyss. Barlem. }\end{array}$ & $\begin{array}{c}\text { Identificar } \\
\text { o perfil das } \\
\text { mulheres } \\
\text { que } \\
\text { oficializa a } \\
\text { queixa } \\
\text { sobre a } \\
\text { violência. }\end{array}$ & $\begin{array}{l}\text { Estudo com } \\
\text { estatística } \\
\text { descritiva. }\end{array}$ & $\begin{array}{c}\text { O maior índice } \\
\text { de vítimas são } \\
\text { mulheres com } \\
\text { características } \\
\text { semelhantes. A } \\
\text { violência fisica } \\
\text { está presente na } \\
\text { metade dos } \\
\text { casos. }\end{array}$ & $\begin{array}{l}\text { Há muitas } \\
\text { formas de } \\
\text { violências } \\
\text { sofridas pelas } \\
\text { mulheres, } \\
\text { como: fisica, } \\
\text { sexual e } \\
\text { psicológica. }\end{array}$ \\
\hline $\begin{array}{c}\text { Experiências de } \\
\text { sobreviventes de } \\
\text { violência sexual } \\
\text { sul-africanos com } \\
\text { profilaxia pós- } \\
\text { exposição e } \\
\text { cuidados de } \\
\text { enfermagem } \\
\text { individualizados. }\end{array}$ & $\begin{array}{l}\text { Elizabeth } \\
\text { Arend; } \\
\text { Anastasia } \\
\text { Maw; } \\
\text { Catherine de } \\
\text { Swardt; } \\
\text { Lynette A. } \\
\text { Denny; } \\
\text { Michelle } \\
\text { Roland. }\end{array}$ & $\begin{array}{l}\text { Avaliar as } \\
\text { experiência } \\
\text { s de } \\
\text { pessoas que } \\
\text { já fizeram } \\
\text { uso do } \\
\text { PEP. }\end{array}$ & $\begin{array}{l}\text { Pesquisa } \\
\text { qualitativa. }\end{array}$ & $\begin{array}{l}\text { Importância dos } \\
\text { enfermeiros no } \\
\text { momento da } \\
\text { assistência. }\end{array}$ & $\begin{array}{l}\text { Reflexos } \\
\text { emocionais e } \\
\text { psicossociais } \\
\text { gerados na } \\
\text { vítima de } \\
\text { violência. }\end{array}$ \\
\hline $\begin{array}{l}\text { Desmascarando } \\
\text { três mitos de } \\
\text { estupro }\end{array}$ & $\begin{array}{l}\text { Carr, Mary; } \\
\text { Thomas, Avis; } \\
\text { Atwood, } \\
\text { Daniel; } \\
\text { Muhar, } \\
\text { Alexandra; } \\
\text { Jarvis, Kristi; } \\
\text { Wewerka, } \\
\text { Sandi. }\end{array}$ & $\begin{array}{l}\text { Identificar } \\
\text { mulheres } \\
\text { que foram } \\
\text { vitimas de } \\
\text { agressão } \\
\text { sexual e } \\
\text { que } \\
\text { sofreram } \\
\text { lesões } \\
\text { fisicas. }\end{array}$ & $\begin{array}{c}\text { Estudo } \\
\text { descritivo } \\
\text { transversal. }\end{array}$ & $\begin{array}{c}\text { Foram } \\
\text { evidenciadas as } \\
\text { seguintes } \\
\text { categorias: } \\
\text { População de } \\
\text { Estudo; Dados } \\
\text { coletados; } \\
\text { Abstração de } \\
\text { dados e Análise } \\
\text { de dados }\end{array}$ & $\begin{array}{c}\text { As vítimas } \\
\text { geralmente } \\
\text { demoram para } \\
\text { comparecer ao } \\
\text { hospital e } \\
\text { raramente tem } \\
\text { alguma lesão } \\
\text { fisica pois na } \\
\text { maioria das } \\
\text { vezes não } \\
\text { exercem força } \\
\text { contra o } \\
\text { agressor. }\end{array}$ \\
\hline $\begin{array}{l}\text { Interseção de HPV } \\
\text { e agressão sexual. }\end{array}$ & $\begin{array}{l}\text { Fontenot, } \\
\text { Holly. }\end{array}$ & $\begin{array}{l}\text { Integrar as } \\
\text { estratégias } \\
\text { de } \\
\text { educação e } \\
\text { prevenção } \\
\text { do HPV em } \\
\text { consultas } \\
\text { com } \\
\text { pacientes } \\
\text { em faixa } \\
\text { etária para } \\
\text { a vacina } \\
\text { contra o } \\
\text { HPV. }\end{array}$ & $\begin{array}{l}\text { Pesquisa } \\
\text { exploratória, } \\
\text { transversal. }\end{array}$ & $\begin{array}{c}\text { A maioria dos } \\
\text { enfermeiros } \\
\text { apoiaram a } \\
\text { educação dos } \\
\text { paciente } \\
\text { contra HPV } \\
\text { por escrita } \\
\text { sobre a vacina } \\
\text { além de } \\
\text { concordarem } \\
\text { que podem ser } \\
\text { feitas algumas } \\
\text { melhorias nas } \\
\text { instruções da } \\
\text { vacina para } \\
\text { esses }\end{array}$ & $\begin{array}{c}\text { A equipe de } \\
\text { enfermagem } \\
\text { presta muitos } \\
\text { cuidados a } \\
\text { adolescentes e } \\
\text { jovens que } \\
\text { foram vítimas } \\
\text { de estupro, } \\
\text { que tem risco } \\
\text { de adquirir } \\
\text { HPV e estão } \\
\text { na faixa etária } \\
\text { da vacina } \\
\text { contra o HPV. }\end{array}$ \\
\hline
\end{tabular}




\begin{tabular}{|c|c|c|c|c|c|}
\hline & & & & adolescentes. & \\
\hline $\begin{array}{l}\text { Năo adesão ao } \\
\text { segmento } \\
\text { ambulatorial por } \\
\text { mulheres que } \\
\text { experienciaram a } \\
\text { violéncia sexual }\end{array}$ & $\begin{array}{l}\text { Tatiane } \\
\text { Herreira } \\
\text { Trigueiro; } \\
\text { Marcelo } \\
\text { Henrique da } \\
\text { Silva; Deise } \\
\text { Moura de } \\
\text { Oliveira; } \\
\text { Maria Cristina } \\
\text { Pinto de Jesus; } \\
\text { Miriam } \\
\text { Aparecida } \\
\text { Barbosa } \\
\text { Merighi; }\end{array}$ & $\begin{array}{l}\text { Compreend } \\
\text { er os } \\
\text { motivos da } \\
\text { não adesão } \\
\text { ao } \\
\text { seguimento } \\
\text { ambulatori } \\
\text { al por } \\
\text { mulheres } \\
\text { que } \\
\text { experiencia } \\
\text { rama a } \\
\text { violência } \\
\text { sexual. }\end{array}$ & $\begin{array}{l}\text { Pesquisa } \\
\text { Qualitativa }\end{array}$ & $\begin{array}{l}\text { A falta de } \\
\text { empatia e } \\
\text { qualificação } \\
\text { dos } \\
\text { profissionais } \\
\text { acaba se } \\
\text { tomando um } \\
\text { dos motivos } \\
\text { dessas } \\
\text { mulheres não } \\
\text { retornarem ou } \\
\text { não } \\
\text { procurarem } \\
\text { um } \\
\text { atendimento } \\
\text { ambulatorial } \\
\text { após a } \\
\text { violência } \\
\text { sofrida. }\end{array}$ & $\begin{array}{l}\text { Mudanças } \\
\text { como: } \\
\text { melhoriae } \\
\text { unificação do } \\
\text { primeiro } \\
\text { atendimento } \\
\text { expondo } \\
\text { menos a } \\
\text { mulher ao } \\
\text { constrangimen } \\
\text { to de declarar } \\
\text { repetidas } \\
\text { vezes o } \\
\text { ocorrido são } \\
\text { maneiras de } \\
\text { criar um } \\
\text { vinculo e } \\
\text { manter a } \\
\text { acessão dessa } \\
\text { vitima a } \\
\text { contimuidade } \\
\text { da assistência. }\end{array}$ \\
\hline $\begin{array}{l}\text { Desafios para } \\
\text { implantação da } \\
\text { cadeia de custódia } \\
\text { para as vitimas de } \\
\text { estupro no Distrito } \\
\text { Federal }\end{array}$ & $\begin{array}{l}\text { Alessandra } \\
\text { Arrais; } \\
\text { Elen Carioca } \\
\text { Zerbini; } \\
\text { Fernanda } \\
\text { Schieber } \\
\text { Saúde Vilas } \\
\text { Boas de } \\
\text { Oliveira Jota; } \\
\text { Renata } \\
\text { Rodrigues de } \\
\text { Melo Almeida; } \\
\text { Arlete } \\
\text { Rodrigues } \\
\text { Chagas da } \\
\text { Costa; } \\
\text { Katiane }\end{array}$ & $\begin{array}{l}\text { Conhecer o } \\
\text { atendiment } \\
\text { o à vítima } \\
\text { de } \\
\text { violelencia } \\
\text { sexual em } \\
\text { maternidad } \\
\text { epública } \\
\text { do DF e } \\
\text { avaliar o } \\
\text { conhecime } \\
\text { nto da } \\
\text { equipe } \\
\text { acerca da } \\
\text { legislação } \\
\text { sobre } \\
\text { cadeia de } \\
\text { custódia. }\end{array}$ & $\begin{array}{l}\text { Estudo } \\
\text { transversal, } \\
\text { quantitativo e } \\
\text { descritivo. }\end{array}$ & $\begin{array}{l}\text { Caracterizaçã } \\
\text { o do } \\
\text { atendimento à } \\
\text { vítima de } \\
\text { violelncia } \\
\text { sexual no } \\
\text { hospital } \\
\text { pesquisado; }\end{array}$ & $\begin{array}{l}\text { Conclui-se } \\
\text { queE } \\
\text { necessária } \\
\text { umamudança } \\
\text { generalizada } \\
\text { de postura } \\
\text { entrea equipe } \\
\text { estudada, para } \\
\text { que seja } \\
\text { possível } \\
\text { implantar a } \\
\text { cadeia de } \\
\text { custódiano } \\
\text { âmbito do } \\
\text { SUS. }\end{array}$ \\
\hline
\end{tabular}




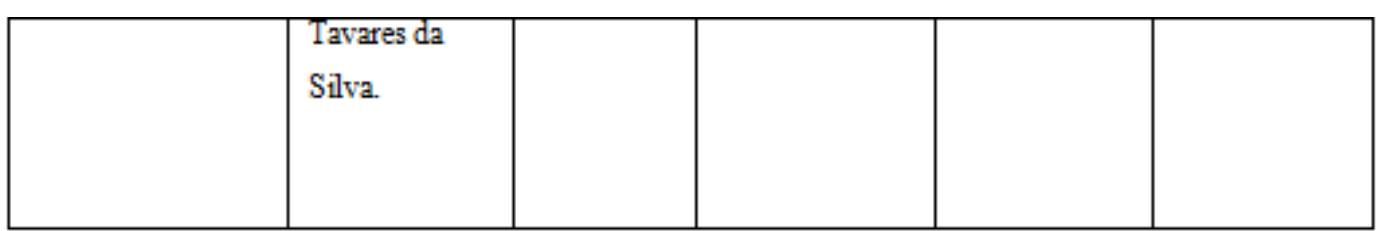

Fonte: Autores

No quadro acima, os autores reuniram os artigos escolhidos para evidenciar as principais informações de cada pesquisa, como: objetivo, metodologia, evidências e considerações finais. Com isso, foi possível notar pontos em comum e divergentes, tendo informações mais diretas e precisas que os auxiliaram no decorrer da elaboração deste trabalho.

Após essas análises, foram construídas as seguintes categorias:

\section{Categoria 1- Aspectos socioculturais do estupro}

Segundo pesquisas de um estudo realizado em dez países, pela Organização Mundial de Saúde, uma a cada seis mulheres sofre algum tipo de violência no mundo, normalmente pelo marido ou namorado. Isso revela que as mulheres estão mais sujeitas a violência no âmbito familiar por seus próprios parceiros (OMS, 2010).

Os Centros Controle e Prevenção de Doença (CDC) relatou que a cada cinco mulheres, uma já sofreu agressão sexual em algum período da vida. A violência sexual contra as mulheres é um problema de Saúde Pública, com isso, está acontecendo uma mudança da forma de lidar com essa questão, como o tratamento das vítimas e quanto a punição dos réus (Carr et al, 2014).

É preciso refletir sobre a prática de violência sexual realizada contra as mulheres. Há um estigma muito grande referente a diferença de gênero. Podendo ocorrer de forma verbal, psicológica, sexual; moral. (Acosta, Gomes \& Barlem, 2013)

Estudos apontam mudanças de comportamento após o sofrimento da violência sexual. O corpo da pessoa violentada mostra sinais, não necessariamente marcas físicas, mas comportamentais. A faixa etária mais acometida por esses casos é dos 15 aos 44 anos. (Acosta et al., 2013)

Porém, profissionais de saúde possuem dificuldades em identificar esse tipo de violência devido ao silêncio das vítimas, falta de capacitação dos profissionais no atendimento a essa vítima, o desconhecimento dos recursos e procedimentos a serem adotados, sentimento de impotência, entre outro. Tais barreiras dificultam na abordagem e identificação a violência. (Sena et. al., 2018).

Profissionais treinados e com olhar ampliado sobre a temática conseguem identificar com maior facilidade as situações que podem sinalizar violência. Através de comportamentos, queixas infundadas, relado de dor genital, sinais de depressão, ansiedade e angústia. (Ferrante et. al., 2009).

A Lei $n^{\circ}$ 12.845/2013 dispõe sobre o atendimento obrigatório e integral de pessoas em situação de violência sexual. Essa lei garante o atendimento emergencial e integral às vítimas de estupro, sejam elas mulheres, crianças, adolescentes e idosos, prevê que esse atendimento seja multidisciplinar, com a ampliação da equipe da emergência contando também com o psicólogo e o assistente social.Essa lei tem por objetivo evitar a peregrinação das vítimas aos órgãos de saúde e justiça logo após o evento da violência. (Ministério da Saúde, 2015).

Em relação a forma de abordagem a questões psicológicas advindas desse trauma não há uma capacitação adequada dos profissionais no atendimento a essa mulher. Evidencia-se a falta de sensibilização quanto aos impactos de um acolhimento 
superficial na emergência para o destrinchar do caso no futuro. A diminuição dos agravos dessa experiência violenta relaciona -se diretamente com tipo de acolhimento que a mulher terá na unidade de pronto atendimento. (Ministério da Saúde, 2001).

A violência sexual é um trauma e uma experiência que aterroriza a vitima, quando uma mulher sofre algum tipo de violência e reflete sobre o ocorrido ela exterioriza as expectativas e considera os impactos deixados pelo evento agressivo, mas para superarem os impactos da violência precisam do apoio familiar e de amigos para que ela se sinta acolhida e amada e de alguma forma impulsionada a seguir em frente, favorecendo a recuperação de sua autoestima retornando a vida normal e deixando esse evento agressivo no passado. (Trigueiro et al., 2018).

Para que o agressor receba a pena pelo ato sexual não consentido é preciso ser comprovados, no entanto é um desafio fazer com que a ação penal seja bem sucedida pois os jurados são pessoas leigas que contam com as testemunhas e provas forenses e precisam ter também o bom senso para que julgue o suposto agressor como culpado ou inocente. (Carr et al., 2014).

Existem mitos no estupro que perduram até os dias de hoje. Os mitos do estupro foram descritos por Burt em 1980 onde o autor definiu como crenças estereotipadas, preconceituosas ou falsas. Esses mitos apoiam a violência sexual e são usados para afirmar ou negar uma agressão sexual contra a mulher (Carr et al., 2014).

Sociedades onde as mulheres e homens são tratados com equidade tem são menos propensas a ter uma cultura de estupro, pois existe menos domínio masculino, já em lugares que a cultura é mais hostil é mais fácil que prevaleça os mitos do estupro. Estudos comprovam que a maioria das vítimas de estupro conhecem seu agressor onde a maior porcentagem é a de parceiros íntimos e de conhecidos, com isso as mulheres tem mais dificuldade de denunciar e procurar ajuda, pois acabam perdoando e a maioria das vítimas acham que são pelo menos parcialmente culpadas (Carr et al., 2014).

Quando a vítima reconhece o agressor como criminoso, mesmo sendo seu parceiro íntimo, os amigos e famílias podem desencorajá-la a fazer uma denúncia pois o cenário não está de acordo com os estereótipos de sua sociedade (Carr et al., 2014).

\section{Categoria 2- $O$ profissional de enfermagem frente às vítimas de estupro}

O abuso sexual gera grande impacto psicológico na vida da vítima e além disso, a mesma fica exposta a infecções sexualmente transmissíveis, HIV e Hepatites virais. Sua saúde física é comprometida, pode haver lesões como hematomas e lacerações genitoanal. No que se refere a saúde mental, pode causar quadros de depressão, ansiedade, isolamento social, síndrome do pânico e outros distúrbios psicossomáticos, inclusive suicídio (Ruxana \& Thomas, 2013).

O Ministério da Saúde sugere que os serviços especializados no atendimento a essas mulheres sejam realizados de forma ambulatorial, com o primeiro atendimento até 72 horas após o evento. A partir de então, os retornos serão agendados para 30 dias, 45 dias, 90 dias e 180 dias após a agressão (Ministério da Saúde, 2012).

No primeiro atendimento a enfermeira realiza o acolhimento, posteriormente a vítima passa pelo médico perito e pelo ginecologista para atendimento clínico, onde são realizados exames laboratoriais e administração de medicamentos (Ministério da Saúde, 2012).

Nos Estudados Unidos, as avaliações feitas na mulher que sofreu a agressão são mais centradas na paciente, como o programa de enfermeira examinadora (SANE), sendo incluso também nas investigações de estupro e o exame de DNA (Carr et al., 2014).

A gravidade das feridas da vítima e a estratégia de resistência da vítima durante a agressão são utilizadas não somente como depoimento para os peritos que irão avaliar o caso mas também como estatística para os estudantes e ao público geral.Outro fator importante na quantidade de lesões é o número de agressores, pois havendo mais agressores a probabilidades de aparecer lesões mais graves é maior (Carr et a.l, 2014). 
Existem 4 categorias de lesões físicas: Nenhuma leve, moderada e grave onde somente as lesões leves não precisam de intervenção médica, lesão leves incluem vermelhidão, inchaço, músculo dolorido, lesões moderadas incluem lacerações superficiais ou ferimentos com força cortante e dente lascado e lesão grave inclui, ossos quebrados, traumatismo craniano, feridas a faca estrangulamento entre outros (Carr et al., 2014).

$\mathrm{Na}$ tentativa de combater algumas patologias há protocolos clínicos e diretrizes terapêuticas para a profilaxia pósexposição (PEP). PEP é um formulário de solicitação de medicamentos de acordo com a profilaxia de cada doença. É preciso que o profissional colete com cautela algumas informações, como: quando ocorreu o abuso, quem realizou essa prática. No manual é possível observar fluxogramas com perguntar que direcionam as respostas necessárias para saber qual é a profilaxia ideal para cada caso (Arend, Maw, Swardt, Denny, \& Roland, 2012)

Muitos profissionais de saúde agem com descuido e falta de respeito ao receber essa vitima, o tempo prolongado de espera do atendimento e falta de discrição também é um problema existente no atendimento a vitimas de violência. Esse é um dos motivos que levam essas vítimas a não procurarem atendimento (Trigueiro et al., 2018).

A equipe de enfermagem possui um papel fundamental no apoio as vítimas de estupro. O ideal é que realize um atendimento humanizado, exercitando a escuta ativa, deve-se estabelecer vínculo, acolher o paciente e fornecer todas as orientações necessárias para os próximos passos nesse período tão delicado (Arend et al., 2012).

Para que haja esse atendimento é necessário ter profissionais qualificados, por isso a importância de realizar cursos de capacitação, palestras e criação de protocolos para desenvolver profissionais com atitudes sensatas e respaldadas na empatia, sensibilidade e ética (Trigueiro et al., 2018).

Tendo em vista que todos os sinais devem ser considerados dentro de um contexto, alguns autores percebem como indispensável a atuação em equipe e a busca de evidências encontradas por outros profissionais que também atendem o adolescente (Fontenot, 2013).

As ações para abordagem da família apresentam-se na forma de orientação aos pais sobre o direito do adolescente de crescer sem violência e os efeitos da mesma para a saúde da vítima, buscando adesão ao tratamento dos agravos resultantes da violência e esclarecendo sobre os deveres dos adultos responsáveis em relação à segurança e ao bem-estar dos adolescentes (Fontenot, 2013).

A obrigatoriedade da notificação é importante não somente pelos danos causados à saúde da vítima e pelo aspecto criminal da violência, mas, também por se constituir um instrumento de proteção e defesa dos direitos de adolescentes vitimados (Fontenot, 2013).

O cuidado a pessoa em situação de violência sexual coloca em evidência a necessidade da corresponsabilização entre ela e o profissional que a atende com vistas à criação de espaços para que ela dê sentido à experiência vivida e supere a agressão sofrida (Trigueiro et al., 2018).

Nesse sentido, ressalta-se a Política Nacional de Humanização (PNH), instituída em 2003, que estimula, entre outras questões, a comunicação entre trabalhadores e usuários, com vistas à construção de processos coletivos de enfrentamento de relações de poder, trabalho e afeto (Ministério da Saúde, 2015).

É imprescindível ressaltar que o apoio emocional por parte da rede de apoio da vítima, espiritual seja qual for sua crença e material são considerados elementos que proporcionam empoderamento para o enfrentamento da situação de violência sofrida (Gomes et al., 2015).

\section{Conclusão}

Em virtude dos aspectos mencionados conclui-se que esse tipo de violência ocorre com qualquer tipo de público, homens, mulheres, crianças e adolescentes, independente de sexo, idade ou orientação sexual. 
O Ministério da Saúde orienta que a vítima precisa ser acolhida segundo suas necessidades e de forma holística. Fator imprescindível na humanização da assistência de enfermagem é estabelecer vínculo, criando uma rede de apoio onde a vítima pode encontrar uma abordagem qualificada. É assegurado por lei o direito ao atendimento emergencial e integral às vítimas de estupro. Essa lei prevê que o atendimento seja multidisciplinar, com a ampliação da equipe da emergência contando também com o psicólogo e o assistente social.

Observou-se a necessidade de realizar cursos de aperfeiçoamento para os profissionais de saúde, melhorando assim, sua abordagem e condutas, para que dessa forma sejam capazes de prestar uma assistência eficaz.

Profissionais qualificados e com olhar ampliado sobre a temática conseguem identificar com maior facilidade as situações que podem sinalizar violência, observam atentamente comportamentos e queixas que podem representar tal agravo a saúde. Em relação ao atendimento emergencial e questões psicológicas, é preciso que ocorra a educação permanente do serviço de saúde, de forma interdisciplinar e multidisciplinar para que se possa atender essa vítima, evitando peregrinação da mesma pelos serviços de saúde.

A partir das pesquisas realizadas para a construção deste estudo, os autores notaram a necessidade de elaborar outras buscas sobre a temática e área envolvidas em questão, aprofundando-se cada vez mais devido a escassez de material existente. Desta maneira, acreditamos que futuramente teremos outros projetos para apresentar e assim, colaborar com a pesquisa, as comunidades acadêmicas e principalmente com a sociedade.

\section{Referências}

Acosta, D. F., Gomes, V. L. O., \&Barlem, E. L. D. (2013). Perfil das ocorrências policiais de violência contra a mulher. Acta Paul Enferm, $26(6), 547-53$.

Arend, E., Maw, A., Swardt, C., Denny, L., \& Roland, M. (2012) Experiências de sobreviventes de violência sexual sul-africanos com profilaxia pósexposição e cuidados de enfermagem individualizados: um estudo qualitativo. Revista da Associação de Enfermeiros em Aids Cuidado,24 (2), $154-165$.

Bardin, L. (2016). Análise de conteúdo. São Paulo: Almedina Brasil.

BRASIL. Lei $\mathrm{n}^{\circ} 12.015$ de 07 de agosto de 2009. Dispõe sobre os crimes contra a dignidade sexual. http://www.planalto.gov.br/ccivil_03/_ato20072010/2009/lei/112015.htm

BRASIL. Ministério da Saúde. Secretaria de Políticas de Saúde. Prevenção e tratamento dos agravos resultantes da violência sexual contra mulheres e adolescentes. Brasília - DF: MS, 2012. 126 p.

Saúde, M., Justiça, M. d., \& para mulheres, S. d. P. (2015). Norma Técnica Atenção Humanização às Pessoas em Situação de Violência Sexual com Registro de Informações e Coleta de Vestígios. MS.

Saúde, M. (2001). Política Nacional de Redução da Morbimortalidade por Acidentes e Violências. http://bvsms.saude.gov.br/bvs/publicacoes/acidentes.pdf

Carr, M., Thomas, A., Atwood, D., Muhar, A., Jarvis, K., \&Wewerka, S. (2014) Desmascarando três mitos de estupro. Journal of Forensic Nursing, p 217225 .

Dempsey, M. (2002).Negative coping as mediator in there lation between violence and outcomes: Inner-city African American youth. American Journal of Orthopsychiatry, 72(1), 102-109. http://pepsic.bvsalud.org/scielo.php?script=sci_nlinks\&ref=101548\&pid=S1413-0394201300010000600009\&lng=pt

Ferrante, F. G., Santos, M. A. d., \& Vieira, E. M. (2009). Violência contra a mulher: percepção dos médicos das unidades básicas de saúde da cidade de Ribeirão Preto, 13(31), 287-299. https://doi.org/10.1590/S1414-32832009000400005

Fontenot, H. (2013) Interseção de HPV e agressão sexual. Journal of Forensic Nursing, 146-154.

Ganong, L.H. (1987). Integrative reviews of nursing research. New Tork, 10(11), 1-11.

Gomes, N. P., Freire Diniz, N. P., dos Santos, L. A., \&Erdmann, A. L. (2015). The social network for confronting conjugal violence: representations of women who experience this health issue, 24(2), 316-324. https://doi.org/http://dx.doi.org/10.1590/0104-07072015002140012

Mendes, K., Silveira, R. C., \& Galvão, C. M. (2008). Revisão integrativa: método de pesquisa para a incorporação de evidências na saúde e na enfermagem. Texto Contexto Enfermagem, Florianópolis, 17(4): 758-64.

Ruxana, J., \& Thomas, L. S. (2013). Health consequences of sexual violence against women, 27(1), 15-26. https://doi.org/10.1016/j.bpobgyn.2012.08.012

Saúde, M. (2012). Prevenção e tratamento dos agravos resultantes da violência sexual contra mulheres e adolescentes: Norma Técnica. Secretaria de Atenção à Saúde, Departamento de Ações Programáticas Estratégicas, (3). https://bvsms.saude.gov.br/bvs/publicacoes/prevencao_agravn

o_violencia_sexual_mulheres_3ed.pdf 
Research, Society and Development, v. 10, n. 4, e15610413895, 2021

(CC BY 4.0) | ISSN 2525-3409 | DOI: http://dx.doi.org/10.33448/rsd-v10i4.13895

Saúde, M. (2015). Estabelece orientações para a organização e integração do atendimento às vítimas de violência sexual pelos profissionais de segurança pública e pelos profissionais de saúde do Sistema Único de Saúde (SUS) quanto à humanização do atendimento e ao registro de informações e coleta de vestígios. Gabinete do Ministro. Portaria Interministerial n.288.

Saúde, O. M. (2010). Prevenindo a violência sexual contra a mulher por parceiro íntimo: atuando e gerando evidências. $O M S$.

Sena, C. A., da Silva, M. A., \&Falbo Neto, G. H. (2018). Incidência de violência sexual em crianças e adolescentes em Recife/Pernambuco no biênio 20122013, 23(5). https://doi.org/10.1590/1413-81232018235.18662016

Trigueiro, T. H., da Silva, M. H., de Oliveira, D. M., Pinto de Jesus, M. C., \& Barbosa Merighi, M. A. (2018). Não Adesão ao seguimento ambulatorial por mulheres que Experienciaram a violência sexual, 27(1). https://doi.org/10.1590/0104-07072018006490015 